\title{
Using a television programme as a tool to increase perceived awareness of mental health and well-being - findings from 'Our Mental Health' survey - ERRATUM
}

\author{
N. McTernan, F. Ryan, E. Williamson, D. Chambers and E. Arensman
}

https:/ /doi.org/10.1017/ipm.2020.8, Published by Cambridge University Press, 04 March 2020

In the original publication, a number of final corrections were omitted. These have now been updated and included.

The Publisher apologises for this oversight.

\section{Reference}

McTernan, N., Ryan F., Williamson E., Chambers D., \& Arensman E. (n.d.). Using a television programme as a tool to increase perceived awareness of mental health and well-being - findings from'OurMental Health' survey. Irish Journal of Psychological Medicine, 1-11. doi: 10.1017/ipm.2020.8 